\title{
Professor iniciante: considerações sobre o seu processo de indução no Ensino Técnico
}

\author{
Claudio Roberto Affonso ${ }^{1}$ \\ Maria de Fátima Ramos Andrade²
}

Ana Silvia Moço Aparício ${ }^{3}$

\section{Resumo}

O presente artigo tem como objetivo geral investigar os desafios e os obstáculos enfrentados, no processo de indução, de professores iniciantes de uma instituição Estadual de Educação Técnica, localizada na cidade de São Paulo. Na pesquisa de campo, foram aplicados questionários e realizadas entrevistas semiestruturadas. Para a análise dos dados, obteve-se apoio dos estudos de Nóvoa (2013), Fiorentini e Crecci (2016), Shulman (2014), Garcia (2010), dentre outros autores que tratam sobre formação inicial, desenvolvimento profissional e processo de indução. Os resultados apontaram que os professores iniciantes entrevistados anseiam por um processo de indução eficaz, que some às suas práticas, propiciando maior compreensão sobre as atribuições inerentes ao professor técnico.

Palavras-chave: Professor Iniciante; Processo de Indução; Desenvolvimento Profissional; Formação de Professores; Formação Inicial.

\section{Beginning teacher: considerations about the induction process in Technical Education}

\section{Abstract}

This article aims to investigate the challenges and obstacles faced, in the induction process, of beginning teachers of a State Technical Education Institution, located in the city of São Paulo. During the field research, questionnaires were applied and semi-structured interviews were conducted. The data analysis was supported by studies from Nóvoa (2013), Fiorentini and Crecci (2016), Shulman (2014), Garcia (2010), among other authors dealing with initial training, professional development and induction process. The results showed that the beginning teachers interviewed desire for a more effective induction process, which summs to their practices, providing a greater understanding of the inherent attributes of the technical teacher.

Keywords: Beginner Teacher; Induction Process; Professional Development; Teacher Training; Initial Formation.

\section{Introdução}

No campo das políticas públicas, o acolhimento do professor iniciante é conhecido como processo de indução (WONG, 2004), ou seja, o período no qual ele ingressa de fato na prática docente, não como aluno, mas como protagonista da sala de aula. Todavia, tal acolhimento pode

\footnotetext{
${ }^{1}$ Centro Estadual de Educação Tecnológica Paula Souza ETEC Getúlio Vargas, São Paulo, e013.contato@etec.sp.gov.br.

2 Universidade Presbiteriana Mackenzie (UPM) e Universidade Municipal de São Caetano do Sul, São Paulo, mfrda@uol.com.br.

${ }^{3}$ Universidade Municipal de São Caetano do Sul, São Caetano do Sul, anaparicio@uol.com.br.
} 
não ocorrer, o que compromete o desenvolvimento profissional do professor iniciante, a qualidade da aprendizagem de seus alunos e, consequentemente, sua permanência na profissão. Diante desse quadro, este artigo se propõe a apresentar uma pesquisa que teve como foco investigar as condições adversas que professores iniciantes de uma Escola Técnica de São Paulo enfrentam ao ingressarem no campo profissional. O texto está organizado em três partes: na primeira, apresentamos os referenciais teóricos que subsidiaram o estudo, na sequência, apresentamos a análise dos dados gerados na pesquisa de campo e, por último, a conclusão do estudo e os referenciais teóricos utilizados no estudo.

\section{Processo de indução: alguns princípios}

A proposta de realizar a indução com apoio profissional aparenta ser um intento moroso e distante no Brasil e na maioria dos países (ALARCÃO; ROLDÃO, 2014) e (ROMANOWSKI; MARTINS, 2013). Há décadas, tal processo vem sendo tratado de forma displicente tanto pela escola quanto pelo poder público, mantendo-se sustentado apenas pela vontade e tenacidade peculiares de professores iniciantes.

A imaturidade profissional não é uma responsabilidade apenas do docente principiante, muito embora as condições desfavoráveis com que ele se depara o faça sentir-se assim. A incumbência de inseri-lo na profissão e contribuir para a construção de sua capacitação docente cabe a toda a comunidade escolar. Ao receber o professor recém-formado, a instituição deveria acolhê-lo, ensinar a ensinar, apontar caminhos e facilitar sua trajetória inicial, oferecendo apoio e condições adequadas ao seu desenvolvimento, uma vez que a prática docente exige formação continuada.

Uma boa indução colabora para que o professor iniciante sane suas dúvidas acerca do cotidiano escolar, enfrente questões mais desafiadoras relacionadas à indisciplina ou dispersão dos estudantes, adquira conhecimentos sobre o manuseio de documentos inerentes à profissão, aprenda sobre a elaboração de aulas, provas e correção, e para que consiga, por fim, desenvolver sua identidade docente e permanecer com confiança na profissão. Segundo Nóvoa: "a participação efectiva dos profissionais na formação de futuros professores é fundamental para que se crie um novo modelo de formação de professores. Não nascemos professores. Tornamo-nos professores 
através de um processo de formação e aprendizagem na profissão" (NÓVOA, 2013, p.230).

O autor defende que a formação de professores deveria ocorrer na escola, ou seja "dentro da profissão", reduto onde esse aspirante irá permanecer durante todo o seu trajeto profissional. Ele afirma que, como os médicos são formadores dos seus discentes, é patente "a necessidade de os professores terem um lugar predominante na formação de seus colegas" (NÓVOA, 2013, p.230).

O professor no Ensino Técnico, quando inicia sua jornada docente, acredita que sua formação acadêmica somada à prática adquirida na indústria, é suficiente para assumir a responsabilidade de exercer sua profissão, integrando seus saberes no conteúdo das disciplinas que irá ministrar.

Diferentemente do que se exige do professor iniciante licenciado que atua nos Ensinos Fundamental e Médio, o professor iniciante do Ensino Técnico, muitas vezes, não é admitido mediante avaliação de seu conhecimento pedagógico, ou seja, não lhe é solicitado o curso de licenciatura. Com isso, quando ingressa no campo da docência, tem a percepção de que não possui uma formação profissional que o capacite a ensinar e, frequentemente, precisa recorrer ao auxílio de seus pares, da coordenação e orientação pedagógicas, com a intenção de esclarecer dúvidas e superar os desafios da profissão.

Ocorre que, em muitos casos, o professor em início de carreira não tem essa rede de apoio. Segundo Garcia (2010), uma das características da profissão docente é o isolamento, sendo os alunos as únicas testemunhas ao longo do percurso de inserção profissional do professor. $\mathrm{O}$ autor também aponta que aumentos salariais, prêmios e reconhecimentos também são fatores de incentivo: "mas sempre na medida em que repercutam na melhora da relação com o conjunto de alunos" (GARCIA, 2010, p.17). Garcia (2010) ainda descreve que muitos estudos sobre o tema indicam que os professores desfrutam de satisfação com o ensino em si e que desenvolvem vínculo afetivo com os alunos. Deste modo, revela o autor que "muitos docentes citam como principal fonte de satisfação o cumprimento da tarefa e os sucessos pedagógicos dos alunos" (p.17).

Romanowsky e Martins (2013) enfocam que o início da carreira docente é marcado por descobertas e desafios que desencadeiam conflitos no professor que se vê confrontado com a necessidade de assumir responsabilidades profissionais, "pois percebe que a incompletude da 
sua formação inicial como referência para as decisões sobre o que fazer e entender o que se passa" (p.2). As autoras mencionam que, apesar de as dificuldades influenciarem diretamente a decisão dos professores iniciantes de permanecer ou não na profissão, uma vez que se trata de um tempo de aprendizagens, as adversidades podem também fazer surgir neles o desejo de superação e ânsia por sobrevivência na carreira docente.

As autoras consideram que as experiências no início da carreira influenciam intimamente a decisão dos docentes principiantes de seguirem ou não na profissão, revelando que o sentimento de solidão é frequente nessa fase de criação de vínculos com seus pares na escola e com a profissão. Concluem que o início da docência "é marcado por intensas descobertas sobre a prática e seus problemas, e sobre as alternativas possíveis para resolvê-los. O apoio dos professores mais experientes possibilita ao iniciante desenvolver um processo de formação na profissão" (ROMANOWSKY; MARTINS, 2013, p.1-2).

Freitas (2002) afirma que é comum deixar as turmas com maior grau de complexidade, tanto nas estratégias didáticas quanto nas disciplinas, para os professores em início de carreira, relatando que são turmas marcadas por uma grande diversidade: "possuem alunos com níveis de aprendizagem desiguais, que, muitas vezes, não possuem os materiais escolares mínimos e pertencem a famílias de baixo poder aquisitivo" (p.160). Segundo Alarcão e Roldão (2014), vários países, embora assumindo lógicas diferentes, estão se organizando em programas de indução docente. As autoras afirmam:

[...] uns privilegiam a obrigatoriedade versus o seu carácter facultativo. Outros têm uma orientação de socialização acrítica em detrimento da preocupação pelo desenvolvimento pessoal, social e profissional. Uns dão mais ênfase à avaliação enquanto outros privilegiam a formação (p.110).

As autoras revelam que vários fatores influenciam o sucesso dos programas, desde "a focalização na atividade profissional em contexto de trabalho real e o clima colaborativo nas escolas" (2014, p.110).

Alarcão e Roldão (2014) alertam que esse início da docência é positivamente determinante para o desenvolvimento da construção da identidade docente e do profissionalismo ou, em casos negativos, para o abandono desse projeto de vida. As autoras 
elencam algumas das dificuldades, desafios que também encontramos na literatura sobre o professor iniciante do Ensino Técnico, embora com maiores agravantes no ensino práticopedagógico e em materiais utilizados nas aulas complementares.

As dificuldades sentidas pelos professores em início de carreira são de vária ordem: científico-pedagógica (gestão de ensino, problemas de indisciplina e desmotivação, diferenciação de ritmos de aprendizagem, gestão do currículo, relacionamento com os alunos, avaliação); burocrática (conhecimento da legislação, dos regulamentos, do funcionamento da escola, diversidade de tarefas e tempo para as gerir, assunção de cargos sem preparação); emocional (autoconhecimento, autoestima e autoconfiança, isolamento, angústias, gestão das dimensões pessoal e profissional); social (identidade e identificação profissional, relacionamento com os colegas, desconhecimento das regras de conduta, relacionamento com os encarregados de educação). É habitual falarse em resolução das dificuldades por tentativas e erro neste período em que aos saberes aprendidos na formação inicial é preciso dar uma orientação prática e contextualizada (ALARCÃO; ROLDÃO, 2014, p.111).

No Brasil, já existem diversos relatos na literatura de alguns breves modelos de indução do professor iniciante (ANDRÉ, 2015), (PRÍNCIPE; ANDRÉ, 2019) e (PASSOS; ANDRADE; APARÍCIO; COSTA, 2020). São programas idealizados pela própria equipe escolar em instituições públicas ou particulares, regidos por diferentes critérios e padrões, dispersos, sem o apoio financeiro ou aval do poder público. Nenhum programa atinge grandes proporções ou tem características para servir de protótipo para outras unidades escolares, de diferentes modalidades de ensino, em todo o território nacional.

A seguir, apresentamos uma pesquisa que foi realizada com professores iniciantes atuantes de uma Escola Técnica Estadual (ETEC), localizada no município de São Paulo.

\section{Pesquisa de campo: o contexto e os participantes}

O campo da pesquisa foi uma instituição de Ensino Técnico. Para identificar quem eram os professores iniciantes da instituição, foi realizado contato com o seu departamento pessoal. Após solicitação, foram enviados, por escrito, os dados de nove professores efetivos com até 5 anos de docência (nome, telefone e e-mail). De posse desse levantamento, os nove professores foram contatados e prontamente aceitaram participar da pesquisa (a documentação foi enviada 
por correio eletrônico). O primeiro passo foi a aplicação de um questionário, com dezoito perguntas (dezessete fechadas e uma aberta). Dos nove professores que responderam aos questionários, seis se dispuseram a participar da entrevista semiestruturada. Foram agendados dia e horário, de acordo com a conveniência e disponibilidade de cada professor. As entrevistas foram gravadas e transcritas. Os profissionais foram escolhidos independentemente da unidade em que trabalham. Para manter o anonimato e preservar a identidade dos docentes, os participantes foram identificados, tanto no questionário quanto nas entrevistas, com as siglas: P1, P2, P3, P4, P5, P6, P7, P8 e P9.

Assim, tais siglas foram utilizadas como referência nas duas modalidades da pesquisa. Os docentes que participaram do estudo são, em sua maioria, do sexo masculino, acima de 35 anos de idade, com até cinco anos de docência no Ensino Técnico efetivo na unidade. Foi observado também que $66 \%$ desses professores têm graduação na área de Exatas, portanto, alguns dos que responderam ao questionário fizeram o curso de Licenciatura oferecido pela própria instituição. Outras observações realizadas: $77 \%$ trabalham também em outras escolas, $22 \%$ não atuam em outras escolas e $44 \%$ exercem atividade não ligada ao ensino. Quanto à formação, $88 \%$ concluíram a Educação Básica em escolas públicas, 33\% se graduaram em universidades públicas e $66 \%$ em universidades privadas, $66 \%$ possuem especialização e $22 \%$ realizaram mestrado. Foi constatado também que 55\% têm jornada semanal entre 20 e $25 \mathrm{~h} / \mathrm{a}$ e $44 \%$ entre 30 e $34 \mathrm{~h} / \mathrm{a}$, com participação de $66 \%$ de professores nos cursos oferecidos pela rede e total de $33 \%$ que ainda não aderiram aos cursos.

Na sequência, apresentam-se os resultados das entrevistas, com breves análises e falas dos professores.

\section{Organização dos dados: as entrevistas}

Dos professores que responderam ao questionário, seis docentes se dispuseram a participar da entrevista. Os dados foram organizados em quadros e, após identificação minuciosa do que foi recorrente, elencamos três eixos para análise. São eles: aprendizagem da docência, os desafios e obstáculos enfrentados no início da docência e as estratégias para o processo de indução. 


\section{Aprendizagem da docência}

Ao serem indagados sobre o percurso formativo, a maioria afirmou que cursou a Educação Básica em escolas públicas. Dos nove professores, quatro fizeram Ensino Técnico, sendo que dois professores estudaram em unidades de Escola Técnica Estadual de São Paulo (ETEC), cursando Marketing e Eletromecânica, especificamente. Os outros dois professores cursaram Tecnologia da Informação e não mencionaram o local em que estudaram. Um dos professores que cursaram o Ensino Técnico em ETEC também realizou mais dois cursos técnicos no Serviço Nacional de Aprendizagem Industrial (SENAI), em Eletrônica e Telecomunicações.

O P1 é graduado em Direito e, posteriormente, fez o curso de Licenciatura oferecido pela instituição.

O P2 é tecnólogo pela Faculdade de Tecnologia de São Paulo (FATEC) e tem mestrado pelo Instituto Técnico da Aeronáutica (ITA).

O P3 é graduado em Pedagogia, com especialização em Filosofia e Sociologia.

O P4 é graduado em Letras com habilitação em Tradução e Interpretação, Propaganda e Marketing na Escola Superior de Propaganda e Marketing (ESPM) e cursou latu sensu em Magistério para o Ensino Superior e Semiótica Psicanalítica, na Pontifícia Universidade Católica (PUC).

O P5 é tecnólogo em Materiais, Processos e Componentes Eletrônicos, graduado em Matemática e cursou Licenciatura na instituição, fez mestrado na área de Microeletrônica, sem mencionar a instituição.

O P6 é tecnólogo em Análise de Sistema, graduado em Matemática, com Licenciatura pela instituição e graduação latu sensu em Gestão.

Os professores, ao serem indagados sobre suas escolhas profissionais - quais os motivos para a escolha da carreira docente -, apontaram aspectos diversificados, conforme pode ser observado a seguir, na transcrição de suas falas:

P1 - Fiz curso técnico na ETEC, já havia dado curso preparatório para Ordem dos Advogados do Brasil (OAB), e soube do concurso do Centro Paula Souza. Já conhecia a instituição em que leciono.

Periódico Horizontes - USF - Itatiba, SP - Brasil - e021057 
P2 - Estava desempregado quando apareceu a oportunidade, mas já havia pensado antes em ser professor.

P3 - "(Queria) ser útil para a humanidade de alguma forma. Sempre fui muito envolvido com trabalhos sociais, desde muito pequeno, e foi o trabalho voluntário, dando aula para jovens em comunidades carentes, que despertou em mim o interesse em fazer Pedagogia. Então, fui para a área docente, motivado por esse interesse em poder fazer a diferença de alguma forma naquilo em que eu me identificava.

P4 - Trabalhei 26 anos no jornal O Estado de S. Paulo. Com o crescimento da internet, a empresa fez um corte de altos salários e muito tempo de casa. Saí de lá e procurei emprego, mas, com 50 anos, eu não encontrava nada. Como tenho uma graduação, pensei em tentar alguma coisa na área acadêmica. Foi quando prestei concurso e passei na ETEC. Me encontrei nisso, gosto disso.

P5 - Foi a necessidade financeira que me motivou, pois, como disse, a empresa que financiava minha bolsa e o projeto de mestrado faliu. Então, não tive outra alternativa senão ir para o mercado de trabalho. Quando apareceu a possibilidade de ministrar pelo centro, achei fantástico! Eu vinha da indústria e pesquisa, tinha a mente de um pesquisador e ela é muito diferente da mente de um docente. $O$ docente vai mais ao âmago, está interessado no aprendizado dos alunos.

P6 - Fui militar durante alguns anos e comecei a gostar de lecionar no Exército, pois dava aulas de assuntos técnicos para militares. Saindo de lá, fui fazer cursos direcionados para o ofício de professor, Licenciatura em Matemática. Na época, tinha uma empresa na área de análise de sistemas e comecei a lecionar no período noturno na ETEC. Após o fechamento da empresa, fiquei somente no Magistério.

Dois professores apontaram que escolheram a profissão docente pois estavam desempregados; dois responderam que a viram como uma possibilidade de trabalho; e dois consideram que optaram pela docência para seguir sua vocação. Os entrevistados, mesmo quando reconheceram não terem planejado ingressar na docência, relataram que desejam permanecer na profissão. Com relação à aprendizagem da docência, a palavra "vocação" foi citada duas vezes. Essa palavra não se revela adequada, pois, o exercício da docência pressupõe um aprendizado constante.

Quando indagados a respeito da importância das contribuições acadêmicas em sua trajetória docente, a maioria afirmou que os conhecimentos pedagógicos foram relevantes para a construção de suas práticas pedagógicas. Segundo Shulman (2014), o conhecimento pedagógico é uma das categorias que compõe a base do conhecimento do professor. As falas a seguir expõem o que foi respondido: 
P1 - A pós-graduação somou, pois lá eu tive matérias específicas de docência, que me ajudaram bastante no dia a dia de sala de aula [...].

P2 - [...] (Obtive na graduação) conhecimento teórico, principalmente na Licenciatura em Física, que me ajudou na prática escolar [...].

P3 - Principalmente a Pedagogia me permitiu olhar para cada indivíduo e perceber a necessidade de trabalhar os meus planos de aula, as minhas metodologias, pensando no desenvolvimento dessas crianças, no desenvolvimento de suas habilidades e capacidades [...].

P4 - Me sinto muito feliz por ter feito Letras, então essa questão da graduação foi muito importante porque me deu desenvoltura na escrita, na fala, na comunicação com os alunos. Você acaba estudando o comportamento, a observação e percepção com o aluno... Isso também contribuiu bastante. [...] essa parte da comunicação, acho que ajudou muito na minha carreira. $E$ também não só a graduação, mas a minha experiência corporativa, fazendo apresentações, dando treinamentos, contribuiu em sala de aula. Comecei trabalhando no Estadão como escriturária e cheguei até a área de coordenação de marketing [...].

P5 - Minha formação acadêmica me trouxe muita bagagem. No meu dia a dia, foi o curso de Pedagogia e o curso de Psicopedagogia (que fizeram diferença). Entender como se constrói o aprendizado do aluno, como se molda a parte cognitiva do aluno, isso é fantástico. Quando você consegue ter os indicativos de que o aluno aprendeu, você sai da sala de aula superfeliz [...].

P6 - Em parte, a formação acadêmica acrescentou, mas eu acredito que a minha vivência na indústria foi importantíssima, pois, no curso técnico, a experiência profissional é fundamental. Só a teoria da formação acadêmica não é suficiente para o curso técnico $[\ldots]$.

Com relação ao processo de aprendizagem da docência, constatou-se que a maioria entende que essa aprendizagem tem sido uma ação mais solitária do que coletiva. Nenhuma experiência de aprendizagem em grupo foi mencionada, ou seja, momentos de trabalho que envolvessem trocas de experiências, discussões da prática, reuniões pedagógicas etc. Garcia (2010) reflete sobre a importância do trabalho de conhecimento coletivo entre os professores em concordância ao trabalho de Cochran-Smith e Lytle ${ }^{4}$, relatando que:

A ideia é que, em matéria de ensino, não há sentido em falar de conhecimento formal e outro conhecimento prático, e sim que o conhecimento se constrói coletivamente dentro das comunidades locais, formada por professores trabalhando em projetos de desenvolvimento da escola, de formação ou de pesquisa colaborativa (COCHRAN-SMITH; LYTLE apud GARCIA, 2010, p.15).

\footnotetext{
${ }^{4}$ COCHRAN-SMITH, M.; LYTLE, S. Relationships of knowledge and practice: teacher learning in communities. Review of Research in Education, p.249-305, 1999.
}

Periódico Horizontes - USF - Itatiba, SP - Brasil - e021057 
O autor afirma que essa segunda categoria de conhecimento é a que melhor caracteriza a profissão docente, que, muito embora seja um trabalho específico e interpessoal, por ser um conhecimento ligado à ação, à comunicação oral, voltado para soluções do cotidiano escolar, possui pouco status e prestígio (GARCIA, 2010). Para exemplificar, foram selecionados os seguintes trechos das entrevistas:

P1 - A minha professora, lá atrás, é meu espelho até hoje. Piso em uma sala de aula e me espelho muito nela como profissional. Em sua dedicação como profissional. Eu acho que é o que me faz cada dia querer aprender mais. São essas referências de outras pessoas, que vejo como grandes professores que tive na vida, que me inspiram. Sei que muitas dessas práticas que eles tinham hoje são ultrapassadas, então hoje tento também me espelhar em docentes que eu admiro, que trabalham comigo e que admiro... Observo docentes do meu ambiente de trabalho e sempre tento pegar práticas pedagógicas deles, para que eu possa aprender cada vez mais. Acho que é meio que uma regra de imitação, digamos assim: eu vou meio que imitando os outros, primeiro meus grandes mestres da vida, depois os grandes professores que tive e, hoje, os grandes professores que me cercam. Assim, vou seguindo os exemplos deles. P2 - Essa é uma pergunta capciosa, porque eu não sei se eu aprendi a ensinar, eu ensino, mas não sei se eu aprendi a ensinar.

P3 - Eu acho que é a junção de duas coisas: na graduação, o professor que está te ensinando a ministrar aulas, ele está olhando um grupo de alunos, está ali com quarenta ou cinquenta futuros professores. Essa é a realidade do professor. Muitas vezes, o professor que está te ensinando a ensinar não teve a prática, então eu acredito que o aprender é uma transformação: é você olhar aquilo que você aprendeu e a realidade em que você está inserido. Eu aprendi muito em cima dos meus erros, eu sou muito perceptivo nesse sentido. No trajeto de volta para casa, me lembro das experiências em sala de aula e percebo quais foram os meus erros para que, na próxima aula, eu consiga fazer de forma diferente. Para mim, o erro e a reflexão sobre ele são primordiais.

P4 - Eu aprendo a ensinar com meus alunos. Sempre digo isso para eles. Digo que não estou na posição de só passar conhecimento... Eu passo o meu conhecimento, mas tenho o conhecimento deles. Esse retorno é importante, principalmente porque eu trabalho com o pessoal da indústria.

P5 - Eu ainda estou aprendendo, a gente aprende todos os dias. Eu tive turmas problemáticas e foram as turmas problemáticas que mais me renderam aprendizados. Há vários canais de aprendizado: quando você faz a captação daquela turma - e eu peguei turmas problemáticas -, você tem uma versão de aula a que você está acostumado. Aí, quando você percebe que grande parte da turma não atingiu o resultado esperado, você tem que mudar os seus métodos, a sua estratégia e a sua sistemática. Como vinha de uma área técnica de pesquisa, eu utilizava artigos para o aprendizado dos alunos, mas não sentia a reciprocidade dos alunos nessa forma de aprendizado, não surtia efeito... Por isso, precisei mudar a estratégia, a sistemática.

P6 - Acho que vem com a prática do dia a dia, não existe manual para isso. Eu

Periódico Horizontes - USF - Itatiba, SP - Brasil - e021057 
dou aulas para adolescentes e para adultos, perfis totalmente diferentes. Os adolescentes já têm a tecnologia incorporada na sua geração, já os adultos têm certas dificuldades de entendimento e manuseio dos procedimentos. Então, eles não podem ser tratados da mesma maneira, temos que ter um "feeling" para dosar de maneira adequada a estratégia de ensino a ser usada em cada caso.

No referencial teórico, ilustrou-se o conceito de desenvolvimento profissional docente. Para tal, serviram de apoio os estudos de Garcia (2010). Segundo o autor, a profissão docente é "a única das profissões nas quais os futuros profissionais se veem expostos a um período mais prolongado de socialização prévia" (GARCIA, 2010, p.12). Nesse sentido, a visão que os professores têm sobre o aprendizado da docência é de que não se trata de um conhecimento que possa advir da prática deles.

Fiorentini e Crecci (2016), ao entrevistarem Cochran-Smith e Lytle, descrevem que as autoras identificam três concepções diferentes da aprendizagem docente, tendo distintos entendimentos e relações que são estabelecidos entre conhecimento teórico e prático.

A primeira concepção, segundo Fiorentini e Crecci (2016), estabelece um relacionamento que as autoras Cochran-Smith e Lytle (1999) denominam de "conhecimento-para-prática", partindo do pressuposto que acadêmicos e especialistas geram conhecimentos formais e teorias para que os professores os absorvam e façam uso deles na prática. Em conformidade com Schön, que é referenciado segundo Fiorentini e Crecci (2016), esse modelo presume que os profissionais resolveriam seus problemas da prática por meio por meio da aplicação de um conhecimento teórico-instrumental.

A segunda concepção já pressupõe que os conhecimentos essenciais para o exercício da docência são de natureza prática, não podendo ser ensinados, mas aprendidos na prática, que pode evoluir com a experiência de outros professores mais experientes ou a partir de reflexões sobre seu próprio exercício docente. Entretanto, esse conhecimento prático dos professores ocorre em contextos pontuais e isolados. Na realidade, com o tempo, as práticas docentes tornam-se rotineiras, impedindo, assim, que o professor e sua docência possam se desenvolver e se transformar continuamente.

Segundo descrevem Fiorentini e Crecci (2016), a terceira concepção nos estudos das pesquisadoras Cochran-Smith e Lytle, aquela que elas denominam de conhecimento-da-prática, 
refere-se a um conhecimento relativo ao ensino, visto como um saber que não pode ser desmembrado em conhecimento formal (ou teórico) e conhecimento prático. Trata-se do conhecimento que os professores necessitam para ensinar e que é gerado quando são levadas em conta as próprias práticas como objeto de investigação intencional. Nessa perspectiva, as teorias de outras produções são tidas como referências que ajudam a problematizar, interpretar e compreender a prática de ensinar. Tratando-se de um conhecimento da prática, de que professores se apossam, eles se apropriam dos conhecimentos advindos da prática trabalhando em comunidades de investigação. E, nessas comunidades, os professores teorizam e constroem seu trabalho, conectados a questões sociais, culturais e políticas, desenvolvendo uma postura que as autoras Cochran-Smith e Lytle caracterizam como investigativas (FIORENTINI; CRECCI, 2016).

\section{Desafios e obstáculos enfrentados no início da docência}

No levantamento sobre os desafios e obstáculos enfrentados pelos professores iniciantes participantes da pesquisa, a maioria apontou que aspectos como a estrutura física, a falta de apoio e de equipamentos ou equipamentos obsoletos atuam como elementos que dificultam a prática pedagógica. As falas a seguir ilustram o que foi dito:

P1 - Também tem uma questão que dificulta que é a questão de estrutura mesmo. Acho que o Centro Paula Souza, tendo esse viés tecnológico, carece muito de estrutura, em especial nas classes descentralizadas, que é onde dou aula nas extensões. Então, na rede, às vezes a gente até tem uma estrutura melhor, mas, nas extensões, a gente trabalha em escolas estaduais que não fornecem um suporte tão grande.

P2 - O primeiro obstáculo que enfrento no meu dia a dia sou eu mesmo como pessoa, quando penso que preciso aprender mais e não ajo nesse sentido. 0 segundo obstáculo tem a ver com a estrutura do ensino, que não facilita a transmissão do conhecimento para o aluno. Isso faz com que a dificuldade em trabalhar com esse aluno seja maior porque, afinal os alunos são heterogêneos. Infelizmente, acabamos tendo de igualar por baixo... Os cursos hoje, de certa forma, servem só para aprimoramento, não necessariamente para que o professor aprenda.

P3 - Há muitos fatores que dificultam. Estrutura física, como um todo, espaço em sala de aula, quantidade de alunos, materiais inadequados, como carteiras e cadeiras. A gente leciona em lousa pintada na parede, enfrentamos uma infraestrutura muito precária. Então, se você não tem equipamentos para

Periódico Horizontes - USF - Itatiba, SP - Brasil - e021057 
ministrar uma aula mais atrativa, fica difícil...

P5 - O que mais dificulta são a infraestrutura e os equipamentos. Eu dou aula de Física, quero propor experimentos e a escola não oferece condições para as disciplinas básicas do Ensino Médio. Eu tenho que usar recursos próprios para levar materiais para a sala de aula. A maior dificuldade mesmo são os recursos físicos, a oferta de materiais para fazer as experiências necessárias. Outro obstáculo é a conscientização dos pais. A conscientização é fundamental, pois o aprendizado é um tripé: a escola, os professores e os pais. Os pais são peças fundamentais para possibilitar uma metodologia diferenciada. Precisam participar mais da vida escolar do aluno.

P6 - O equipamento é ponto mais problemático. Nessa área de tecnologia, não adianta ter só a parte de lousa e giz, o aluno precisa da prática e, às vezes, o equipamento, dependendo da escola, não é apropriado para o tipo de aula que você vai dar. O software, o equipamento muitas vezes já estão obsoletos... $\mathrm{O}$ Estado não tem os subsídios para abastecer todas as escolas com a tecnologia que o professor necessita para dar aula. Por exemplo: aula de Autocad, aulas com vídeos, imagens... Os computadores deveriam ser potentes. Eu tento chegar o mais próximo disso, ofereço recursos compatíveis para poder instruir o aluno. Procuro usar recursos virtuais para suprir a parte física.

Constata-se, com as respostas acima, algumas dificuldades quanto à falta de infraestrutura, pois faltavam laboratórios para o desenvolvimento de aulas práticas e realização de experimentos. Além desses aspectos, um participante da pesquisa apontou que a falta de experiência na área é um obstáculo por ele enfrentado. Ele disse: "O primeiro obstáculo que enfrento no meu dia a dia sou eu mesmo como pessoa, quando penso que preciso aprender mais e não ajo nesse sentido" (P2). Vale ressaltar que o desenvolvimento profissional do professor depende tanto de uma ação que parta dele próprio quanto de ações que a escola precisa promover. É comum o professor acreditar que a sua formação depende exclusivamente de seu empenho. O P2 percebeu que precisa continuar aprendendo e que os cursos oferecidos, muitas vezes, não vêm contribuindo para o seu aprendizado, relatando que "os cursos hoje, de certa forma, servem só para aprimoramento, não necessariamente para que o professor aprenda" (P2).

Apesar de haver orientações oficiais do MEC (BRASIL, 2002) propondo que as secretarias estaduais e municipais deem suporte para o desenvolvimento profissional de professores e gestores nos horários extraclasse, com estudos coletivos na avaliação de resultados e planejamento pedagógico, que fora institucionalizado no final da década de 1980 em São Paulo, Fiorentini e Crecci (2013) afirmam que o estudo mostra como o Horário de Trabalho Pedagógico Coletivo (HTPC) "tornou-se um espaço controlado burocraticamente pelos gestores escolares, 
sendo geralmente obrigados a reportar, às diretorias de ensino, relatórios, por exemplo, sobre o desempenho dos alunos nas avaliações externas" (FIORENTINI; CRECCI, 2013, p.15).

Em suma, ressaltam os autores que:

Logo, as políticas públicas vinculadas às avaliações e aos testes têm comprometido o desenvolvimento profissional dos professores que fica à mercê de uma política de prestação de contas, em detrimento da realização de estudos que tomam a prática de ensinar como objeto de reflexão e investigação (FIORENTINI; CRECCI, 2013, p.15).

Com relação aos primeiros meses na escola, os professores entrevistados fizeram relatos sobre os seus aprendizados iniciais. Sobre o contato com os alunos, os professores e a equipe gestora, eles afirmaram:

P1- Eu lembro que conversei com o coordenador na época e ele me falou: leia os planos de curso. Dei uma boa lida nos planos de curso e isso já me abriu a mente para poder entender quem era o profissional que eu estava formando. Mas a maior ajuda mesmo veio de colegas.

P2 - Nos primeiros três meses, assumi três disciplinas. Tive que estudar todo o conteúdo porque eu não lembrava mais. Isso é obrigação do professor: ir atrás desse conhecimento. Mas isso não foi um problema. A maior dificuldade foi a parte burocrática de como fazer os planos de aula e os Planos de Trabalho Docente (PTD's). Nisso, eu ficava muito perdido... Quem me ajudou foi um professor, um colega de trabalho.

P3 - Nessa questão do acolhimento, eu não tive problemas, porque sou uma pessoa que, quando tem dúvidas, vou atrás, não fico esperando bater na porta. Então, as duas ETECs em que eu iniciei foram bem acolhedoras, não tenho do que reclamar. Tive acolhimento da equipe gestora e dos professores. Eu não era da Educação e, no início, tive muita dificuldade para entender a linguagem da ETEC. Por exemplo: o lançamento no Novo Sistema de Ensino (NSA), plano de aula, plano de curso, muita dificuldade para entender o que era tudo isso.

P4-Eu desconhecia tudo, era cobrada e pensava "o que é isso?". Era um mundo novo para mim, mas eu pedia ajuda aos colegas e eles foram maravilhosos. Sempre me apoiaram, foram muitos os profissionais que me ajudaram.

P5 - Como relatei, fui muito bem recebido. Acho que foi uma das melhores recepções que tive em todo ambiente de ensino em que trabalhei. Nem nas pesquisas que fiz e em outros ambientes de trabalho fui tão acolhido. A ETEC em que comecei era pequena, acho que as escolas pequenas são mais acolhedoras.

P6 - Quando comecei a lecionar, fiquei um pouco assustado, os professores experientes já têm a sua rotina, eles não dão atenção para os iniciantes, acham que os novatos têm que percorrer o seu caminho sem ajuda. Mas você sempre encontra um professor que oferece ajuda. Eu tive experiências boas de 
professores que me auxiliaram na vida acadêmica, "olha, não é assim que se faz, é desse jeito". Tive experiências boas nessa área, inclusive na área militar, onde o sistema é bem rígido. Tentei trazer a experiência da área militar, mas não deu certo, então tive que ajustar isso. Se for rígido demais, os alunos não vão entender, não irão assimilar, então fui aprendendo com os outros professores como aplicar as metodologias, exercícios, fui mesclando e aplicando a tecnologia, chegando ao padrão das aulas que hoje leciono. A gestão me auxiliou na entrega dos relatórios, mas na parte pedagógica tive auxílio somente dos professores.

Segundo os professores, os primeiros aprendizados não foram propiciados pela instituição. Todos afirmaram que recorreram aos colegas mais próximos. Percebe-se que não há um programa institucional de indução do professor iniciante. A maioria relatou que enfrentou dificuldades consideradas "burocráticas" (preenchimento de documentos que são renovados a cada semestre).

Enfim, os primeiros aprendizados foram propiciados pelos colegas mais próximos que se mostravam disponíveis em colaborar. Como se sabe, contar com a disponibilidade do colega, no início de carreira, é importante. Ter um professor experiente acompanhando um professor iniciante pode ajudar no processo de indução. Contudo, ações institucionalizadas ainda não são uma realidade.

Autores como Garcia (2010) já apontaram a importância de o professor experiente acompanhar o professor iniciante no processo de indução, descrevendo esse assessoramento por meio de outros professores, podendo ser colegas ou mentores. Esses conselheiros, mentores, são professores de universidades, diretores de escolas e supervisores experientes, selecionados para ajudar o professor iniciante "um professor com experiência que assiste o novo professor e o ajuda a compreender a cultura da escola" (GARCIA, 2010, p.39).

O início da carreira, segundo Alarcão e Roldão (2014), é

um tempo de verdadeiramente se tornar professor (FULLER E BROWN, 1975, KORTHAGEN, 2001), sentindo a responsabilidade pela aprendizagem dos seus alunos e o equilíbrio da dinâmica relacional (KANE E RUSSEL, 2005). É um tempo de reorientação interna entre o que foi idealizado e o que é a realidade, reorientação que pode ser ajudada por apoio externo, se esse existir, sendo que, nesse caso, é necessário estar-se atento ao risco de uma socialização modelizante e uniformizante que asfixia a criatividade e a pessoalidade (ALARCÃO; ROLDÃO, 2014, p.111). 
Reforçando as falas anteriores, os professores, ao enfrentarem dificuldades, recorreram, em sua maioria, aos colegas mais próximos:

P1 - O meu maior apoio foi dos meus colegas de trabalho mesmo, dos professores que me cercavam. Por exemplo: eu não tinha ideia do que era um plano de trabalho docente, um PTD, e eu tinha que entregar um PTD. Os colegas ao meu redor foram me ensinando o que era um PTD, como se fazia um plano de aula.

P2 - A ajuda veio de dois professores que, na época, trabalhavam na escola. Eles falavam: "tem que fazer dessa maneira, tem que ser feito dessa forma, tem que entrar tal horário". Essas regrinhas foram mais explicitadas por esses dois colegas do que pela equipe gestora. Como fazer um PTD, como não fazer, qual era o jeito certo, qual era o jeito errado. Em relação à disciplina na sala de aula, não tive problemas. Como eu era do Ensino Técnico noturno, eu não tive problemas. Nesse turno, o aluno quando não quer aprender, ele nem entra em sala de aula.

P3 - Sempre que precisava, eu recorria à ajuda tanto de professores quanto da coordenação. Eu não tive problemas. A gente tem uma infinidade de amigos na área da Educação, então você vai pedir ajuda para aquele que está aberto a você. Tem aqueles que nem olham para você, mas tem aqueles que são uma página aberta para você recorrer a qualquer momento. Eu tive essas duas esferas e é claro que recorri à esfera que me ajudou.

P4 - Quando eu iniciei, na verdade não foi bom... Comecei a dar aula no ETIM (Ensino Técnico Integrado ao Médio) e eu não tenho o perfil. Tudo aconteceu muito rápido: eu cheguei e já fui assumindo as aulas, entrando na sala e começando... Senti muita dificuldade, pois não conhecia meus alunos e não tinha afinidade com eles. Acho que existe uma ideia de que é na Licenciatura que você adquire esse treinamento e os professores do Ensino Técnico não têm essa vivência de Licenciatura.

P5 - Praticamente não tive dificuldades. Fazíamos reuniões pedagógicas em que sempre era explicado que o ambiente acadêmico era diferente do ambiente escolar. A gente simulava várias situações... A formação que tive na ETEC, em 1990, é bem diferente da oferecida pela ETEC hoje. Se eu for lecionar com a mesma metodologia dada em 1990, os alunos não irão aprender, ou seja, o objetivo não será alcançado.

P6 - Como já disse, tive ajuda dos colegas mais próximos, inclusive assistindo às aulas de outros professores e fazendo uma parceria nas aulas.

Não se percebe nas falas dos professores dificuldades relacionadas ao aprendizado dos alunos, aos métodos de ensino utilizados e aos instrumentos de avaliação. Ao que parece, a fase de inserção na prática docente é um momento de sobrevivência permeado por tantas outras dificuldades que os aspectos relacionados ao aprendizado dos alunos acabam ficando em segundo plano.

Periódico Horizontes - USF - Itatiba, SP - Brasil - e021057 
Para Alarcão e Roldão (2014), "é habitual falar-se em resolução das dificuldades por tentativas e erros, nesse período em que aos saberes aprendidos na formação inicial é preciso dar uma orientação prática e contextualizada" (ALARCÃO; ROLDÃO, 2014, p.111). Diante das adversidades enfrentadas, foi perguntado se, em algum momento, os professores pensaram em desistir. Os docentes entrevistados afirmaram que:

P1 - Olha, talvez no começo não... Eu estava empolgado, digamos assim, apesar de enfrentando todas as dificuldades... Mas, mais ou menos entre o meu contrato terminado e o meu contrato indeterminado, eu pensei sim em desistir. Confesso que pensei: "ah não, deixa pra lá... Já tá bom, já vi como é a experiência de trabalhar no Centro Paula Souza, bola pra frente".

P2 - Várias vezes pensei em desistir por questões financeiras. O salário é muito baixo. A desistência seria uma escolha puramente econômica.

P3 - Não, desistir da Educação nunca. Mas trocar de escola sim. Até agora eu penso. Não pela estrutura física, pois ela é semelhante, não muda muito de uma escola para outra. Mas já tive vontade de mudar de ETEC por conta de gestão. Isso aconteceu no passado.

P4 - Sim, pensei, pensei logo no início, quando comecei a trabalhar no ETIM. Eu ficava esgotada, acho que Educação não é só conhecimento, mas também comportamento. Respeito por uma pessoa mais velha, por um professor, é essencial. E eu sinto que essa geração é muito debochada, esses jovens podem tudo... Como eu sempre valorizei o respeito pelo outro, isso me causou incômodo a ponto de não querer ficar. Claro que temos problemas também com adultos, tanto de professores como de alunos, mas com o passar do tempo fui me acostumando, mudando, e também vieram recompensas como reconhecimento, participação na evolução dos alunos, ver o meu trabalho recompensado... Isso tudo é gratificante... Eu falo para os meus alunos: vocês têm que sair da minha aula, diferentes. Se saírem do mesmo jeito que entraram, então minha aula não valeu nada.

P5 - Sim, principalmente no começo. Mesmo com as orientações, você traz a parte acadêmica como se fosse um carma... Até você se moldar para ser aberto ao outro lado, é difícil... Você dá uma prova e os alunos vão mal, aí você reflete e conclui "olha, agora não é mais como antigamente, se você der aula desse modo, essa aula servirá para você e não para esses alunos". O nosso histórico de aluno é muito marcante e não adianta querer trazer os métodos antigos para os dias de hoje... Não dá certo, o objetivo não é atingido... Mas, até assimilar isso, leva tempo.

P6 - Não, eu sou perseverante nessa parte. Via professores chateados, mas como sempre tem um exemplo de um professor que conseguiu suprir uma necessidade através da ajuda de outro colega, isso me animava. Eu pensava: comigo tem que dar certo também! Eu gosto do que faço, é muito gratificante contribuir para a mudança de vida das pessoas. Esse é o resultado que eu quero, não é nem pelo dinheiro, não existe professor que fique rico, só o mérito de transformar a vida de uma pessoa através da Educação já vale tudo. 
Nas narrativas sobre a desistência, percebe-se que quase todos pensaram em desistir por conta das dificuldades de adaptação, salário, esgotamento e desarmonia entre a formação acadêmica e a realidade escolar. Mas, a partir da observação dos exemplos de outros professores, com o passar do tempo os professores entrevistados construíram razões para optar pela permanência na docência, assimilando e/ou amenizando as dificuldades, superando, cada um a sua maneira, os sentimentos que instigam o abandono precoce da profissão. Acerca disso, Huberman (2000) comenta:

O aspecto da sobrevivência traduz o que se chama vulgarmente de choque do real, a confrontação inicial com a complexidade da situação profissional: o tatear constante, a preocupação consigo próprio (estou-me a aguentar), a distância entre os ideais e as realidades quotidianas da sala de aula, a fragmentação do trabalho, a dificuldade em fazer face, simultaneamente, à relação pedagógica e à transmissão de conhecimentos, a oscilação entre relações demasiado íntimas e demasiado distantes, dificuldades com alunos que criam problemas, com material didático inadequado [...] Em contrapartida, o aspecto da descoberta traduz o entusiasmo inicial, a experimentação, a exaltação por estar, finalmente em situação de responsabilidade (HUBERMAN, 2000, p.39).

Huberman (2000), ao discutir o conceito de desenvolvimento profissional, afirma a importância de olharmos a docência como algo que se aprende e diz que, para avançarmos, é de extrema importância a escola propiciar condições de aprendizado para o professor. $\mathrm{O}$ autor reflete que o desenvolvimento da carreira docente é um processo e não acontecimentos em série. $\mathrm{O}$ autor destaca:

o fato de que encontrarmos sequências-tipo não impede que muitas pessoas nunca deixem de praticar a exploração, ou que nunca estabilizem, ou que desestabilizem por razões de ordem psicológicas (Tomada de consciência, mudança de interesse e valores) ou externas (acidentes, alterações políticas, crise económica) (HUBERMAN, 2000, p.38).

\section{As estratégias para o processo de indução}

Dentre as estratégias evidenciadas nas entrevistas, destacam-se o treinamento presencial para lidar com os registros escolares, a elaboração de um documento (manual) sobre 
as regras da escola, capacitação contínua focada em assuntos pertinentes em harmonia com o horário de trabalho, assistir aulas de outros professores mais experientes para adquirir maior segurança, afastamento inicial das aulas para assimilação dos procedimentos, curso ou treinamento na área pedagógica no início da atividade docente, além da troca de experiências relevantes ao professor do Ensino Técnico. Também foi mencionada a necessidade de cursos relacionados à área da Pedagogia.

Constatou-se, a partir dos apontamentos, que, para os professores iniciantes, o desenvolvimento profissional depende de ações externas. Para eles, um bom acolhimento passa pela oferta de cursos e de instruções a serem ofertadas pela escola. Essa visão não contempla o que, de fato, seria um bom projeto de acolhimento, visto que apenas a oferta de cursos e manuais não será suficiente para desencadear, no professor iniciante, as condições necessárias para o seu desenvolvimento profissional.

Abaixo, algumas das estratégias abordadas pelos professores entrevistados nessa pesquisa:

P.1 - Eu acho que, em termos formativos, o antigo esquema, que hoje eles chamam de formação pedagógica, deveria ser o ponto inicial, já que, no Centro Paula Souza, são acolhidos bacharéis, então você não precisa ser necessariamente licenciado para ministrar o curso técnico. Agora, como estratégia de acolhimento, penso que, antes de o professor entrar em sala de aula, deveria acontecer esse acolhimento. Toda empresa tem uma semana de acolhimento, digamos assim. É quando o professor iria conhecer as instalações, saber de suas atribuições, conhecer o manual de atuação do professor...

P.2 - Acredito que, primeiro, a equipe gestora deveria desenvolver cursos voltados para criação e desenvolvimento de PTDs, como manipular o Sistema de Gestão Educacional (SIGA) de forma correta e de forma clara etc. Quanto ao acolhimento, deveria estar diretamente voltado ao momento de chegada do professor. A capacitação deve ser contínua, acontecendo com um rodízio entre todos os professores das áreas afins. Cursos presenciais voltados para o domínio dos registros escolares, conhecimento das regras da escola, treinamento dos equipamentos do laboratório e oficinas com professores que dominam esse conhecimento são outras estratégias possíveis.

P.3 - Eu diria que deveria ter um curso dentro do Centro Paula Souza que preparasse os profissionais antes de eles entrarem na sala de aula, explicando quais são as metodologias. $O$ ideal é que tivesse uma estrutura: um vice-diretor para a base comum, um vice-diretor para a base técnica, para que as coisas se desenrolassem melhor. Preparação dos professores antes da entrada em aula, treinamento nos registros escolares, orientação e formação continuada, dando suporte às mudanças necessárias, suporte com mais funcionários auxiliando o professor. Tudo isso poderia ser feito.

P.4 - Sem dúvida, deveria haver treinamento. Deveríamos parar com tantos

Periódico Horizontes - USF - Itatiba, SP - Brasil - e021057 
trabalhos burocráticos e repetitivos que não levam a nada. Me diga o que isso contribui para minha evolução, para a evolução do aluno, para a evolução da escola? Eu sou totalmente a favor de você ter uma organização de documentos, de manuais, tem que ter, mas parece que muita coisa é inventada para dar trabalho para o professor. Acho importante que, no início da carreira, os professores devam ser afastados para treinamento, mentoria e acompanhamento. É desenvolvimento pessoal, desenvolvimento do recurso humano que você tem. É investimento.

P.5 - Nesse começo, uma boa estratégia seria colocar o professor iniciante acompanhando as aulas de professores mais experientes. Seria interessante que, pelo menos nas primeiras semanas, ele acompanhasse como o professor faz a comunicação na sala de aula com o aluno, como ele apresenta o conteúdo, como ele tem os indicativos de que o aluno teve esse saber interiorizado. Por isso o professor que vem só com graduação necessitaria dessas semanas para observação e acompanhamento do professor. Os cursos de Licenciatura deveriam ter um enfoque mais prático: tem muita teoria e pouca prática.

P.6 - Primeiro, deveria existir um plano eficaz de carreira. Não existe isso no Centro. Os professores têm uma evolução e têm que custear os estudos e lecionar ao mesmo tempo. $O$ conhecimento adquirido não é usado na carreira... Deveria ter uma mentoria para os professores iniciantes. Reuniões de troca de experiência docente, para traçar perfis de alunos, compartilhar informações sobre docência e problemas do dia a dia. Reduzir a burocracia também seria excelente.

Os professores iniciantes sentem o impacto da realidade escolar e, com o passar do tempo, vão se isolando por sentirem que o conhecimento adquirido na formação inicial não é suficiente para o exercício da docência. Lembrando que muitos professores que atuam no Ensino Técnico são bacharéis em áreas técnicas e que, portanto, não tiveram nenhum contato com a Pedagogia e as técnicas de ensino e aprendizagem. Garcia (2010) expõe que, nesse período, deve ser transmitida a cultura docente ao professor iniciante (os conhecimentos, modelos, valores e símbolos da profissão), adaptando-a ao entorno social em que se desenvolvem as atividades docentes: "No momento, tal adaptação pode ser fácil quando o entorno sociocultural coincide com as características do professor iniciante. No entanto, tal processo pode ser mais difícil quando deve-se integrar a cultura que lhes são desconhecidas até o momento de começar a ensinar" (GARCIA, 2010, p.30).

O autor afirma ainda que:

Os primeiros anos são fundamentais para assegurar o professorado motivado, envolvido e comprometido com a profissão... Na realidade, se observarmos como as profissões incorporam e socializam os novos membros, percebemos o 
grau de desenvolvimento e de estruturação que tem essas profissões (GARCIA, 2010, p.32).

Diferentemente do que ocorre em algumas profissões, na docência, é necessário um tempo maior para o profissional principiante se estabelecer e realmente "sentir-se professor". Nóvoa (2017), nos estudos sobre essa questão do aprender a ser professor e aprender a sentirse como professor revela que, ao entrar para o ensino ou a medicina, não é como entrar em outro curso qualquer. É preciso motivação, perfil e predisposição para ser professor. Se para se formar médico é preciso estar entre médicos e vivenciar as instituições de saúde, do mesmo modo, para se formar professor é preciso estar entre professores e vivenciar as instituições escolares.

\section{Conclusão}

O propósito dessa pesquisa foi analisar as dificuldades de professores iniciantes no Ensino Técnico. Analisando o resultado da pesquisa, constatou-se que não existe uma "cultura do acolhimento" embora, esporadicamente, algumas ações isoladas possam acontecer.

De posse do levantamento, na pesquisa de campo, professores iniciantes responderam aos questionários e participaram das entrevistas com perguntas semiestruturadas. Os dados, organizados em tabelas, foram analisados a partir de três eixos para análise: aprendizagem da docência, os desafios e obstáculos enfrentados no início da docência e as estratégias para o processo de indução. Os professores relataram dificuldades com a cobrança e com preenchimento dos documentos, às vezes repetitivos ou redundantes, e queixaram-se da carência de um treinamento apropriado. Eles também indicaram que, no início da profissão, não é dado tempo para que o docente assimile, aos poucos, os trâmites.

Diante das dificuldades encontradas, todos os professores entrevistados, sem exceção, recorreram à ajuda de colegas mais experientes para obter apoio. Nos relatos, verificou-se também que, nesse início solitário, eles optaram por se inspirar em modelos e didáticas de bons professores.

Outro aspecto constatado nas entrevistas é a falta de cursos mais relacionados aos problemas que enfrentam. Todos valorizaram, em suas falas, a importância do conhecimento 
pedagógico. Por serem, em sua maioria, bacharéis, ao ingressarem na profissão docente sentem a necessidade de cursar a Licenciatura. Exemplificando: para o curso de Engenharia, não existe Licenciatura, somente Bacharelado, e são esses bacharéis que compõem praticamente a maior porcentagem do corpo docente dos professores egressos da graduação e da indústria no Ensino Técnico. Logo, segundo os participantes, a necessidade de capacitação pedagógica é imprescindível e urgente. Em seu ingresso na profissão, desprovidos da vivência docente, os professores trazem para a sala suas práticas anteriores, suas experiências da vida profissional fora da Educação e isso nem sempre surte o efeito desejado.

Os professores lembraram-se de aspectos que Nóvoa (2013) já criticava: uma formação que não considera a dinâmica dos problemas que os docentes enfrentam em sala de aula. $O$ autor afirma que a formação de professores é mais dominada por referências externas do que pelo próprio trabalho docente. "Não houve uma reflexão que permitisse transformar a prática em conhecimento" (NÓVOA, 2013, p.228). Segundo o autor, essa formação deveria ocorrer dentro da profissão docente, revelando "a necessidade de os professores terem um lugar predominante na formação de seus colegas" (NÓVOA, 2013, p.230).

Não se nasce professor. O processo de aprendizagem na profissão deveria acontecer na escola e com outros professores, pois "Quem forma os médicos são outros médicos. O mesmo deveria acontecer na profissão docente" (NÓVOA, 2013, p.230).

$\mathrm{Na}$ análise dos dados ficou evidente que, para os professores iniciantes, a estrutura física é um grande obstáculo a ser enfrentado. Como se sabe, em um curso técnico profissionalizante, a estrutura física, disposição, manutenção e organização dos equipamentos de laboratório e oficinas são importantes para o bom andamento da aula, assim como também o espaço físico adequado. A quantidade máxima de alunos em classe tem relação direta com a qualidade da aula. Os professores entrevistados apontam certa deficiência em relação a esses quesitos. Diferentemente de aulas teóricas que requerem salas onde exista somente uma lousa, as aulas laboratoriais de disciplinas específicas do Ensino Técnico profissionalizante necessitam de condições específicas, principalmente para os professores iniciantes.

Muitos relataram que o domínio dos equipamentos e aparatos que são propícios para as aulas práticas revela-se um grande desafio. O domínio desses instrumentos por parte do professor é imprescindível, afinal é nos laboratórios e nas oficinas que a teoria se transforma em 
algo palpável, que tem o poder de encantar os alunos. É ali que o aluno percebe a utilidade da teoria e porque é importante a prática, respondendo à pergunta rotineira dos alunos para os professores: "Para que serve isso, professor?".

Como relatam L.Darling-Hammond e J. Bransford (2019), é preciso concentrar-se naquilo que é importante aprender, sem desviar a atenção dos objetivos reais do ensino. Aponta a autora: "O ensino em sala de aula deve envolver os alunos em atividades de aprendizagem que sejam, na medida do possível, exemplos dos objetivos reais de aprendizagem" (DARLINGHAMMOND; BRANSFORD, 2019, p.239). Nessa questão, os autores exemplificam que, se nosso objetivo é fazer os alunos lerem livros, jornais e poemas, eles devem fazê-lo e não receberem materiais simuladores, com a exceção da adequação à idade. Darling- Hammond e Bransford (2019) revelam ainda que:

[...] Da mesma forma, se quisermos que os alunos consigam raciocinar e utilizar o conhecimento científico nas ciências, eles devem receber a oportunidade de descobrir como as coisas funcionam, realizando investigações e desenvolvendo explicações nas próprias palavras que conectam suas experiências com as teorias dos livros didáticos (DARLING-HAMMOND; BRANSFORD, 2019, p.239).

Também foi perceptível, nas falas dos professores participantes, que a aprendizagem dos alunos não foi vista como um obstáculo no início de sua trajetória docente. Apesar de concordarem com a necessidade da realização de cursos pedagógicos, não apareceram em seus depoimentos as possíveis relações entre os conhecimentos pedagógicos com os conhecimentos do conteúdo. Uma possível justificativa para isso talvez seja o fato de que existem tantas adversidades a serem enfrentadas na inserção do professor iniciante, que a questão do aprendizado deixa de sobressair nesse período.

\section{Referências}

ALARCÃO, I; ROLDÃO, M. C. Um passo importante no desenvolvimento profissional dos professores: o ano de indução. Revista Brasileira de Pesquisa sobre Formação Docente, v.6, n.11, p.109-126, ago./dez. 2014. Disponível em: https://revformacaodocente.com.br/index.php/rbpfp/article/view/108/97. Acesso em: 3 mai. 2020. 
ANDRÉ, M. E. D. A. Políticas de formação: continuada e de inserção à docência no Brasil. Educação Unisinos, São Leopoldo-RS, v.19, n.1, p.34-44, jan./abr. 2015.

BRASIL. Ministério de Educação e de Desportos. Conselho Nacional de Educação. Diretrizes Curriculares Nacionais para a formação de professores de educação básica, em nível superior, curso de licenciatura, de graduação plena. DF. MEC/CNE, 2002. Disponível em: http://portal.mec.gov.br/cne/arquivos/pdf/rcp01_02.pdf. Acesso em: 14 set. 2021.

DARLING-HAMMOND, L.; BRANSFORD, J. Preparando os professores para um mundo em transformação. Porto Alegre: Editora Penso, 2019.

FIORENTINI, D.; CRECCI, V. Desenvolvimento profissional docente: um termo guarda-chuva ou um novo sentido à formação? Formação Docente - Revista Brasileira de Pesquisa sobre Formação de Professores, v.5, n.8, p.11-23, 30 jun. 2013. Disponível em: https://revformacaodocente.com.br/index.php/rbpfp/article/view/74. Acesso em: 14 set. 2021.

FIORENTINI, D.; CRECCI, V. Interlocuções com Marilyn Cochran-Smith sobre aprendizagem e pesquisa do professor em comunicações investigativas. Revista Brasileira de Educação, v.21, n.65, p.505-524, abr.-jun. 2016. Disponível em: https://www.scielo.br/j/rbedu/a/963WMFQkZkK8cSFq5gmDQZm/?format=pdf. DOI: http://dx.doi.org/10.1590/S1413-24782016216526. Acesso em: 14 set. 2021.

FREITAS. M. N. C. Organização escolar e socialização profissional de professores iniciantes. Caderno de Pesquisa, n.115, p.155-172, março/2002. Disponível em: https://www.scielo.br/pdf/cp/n115/a06n115.pdf. Acesso em: 09 mar. 2021.

GARCIA, C. M. O professor iniciante, a prática pedagógica e o sentido da experiência. Revista Brasileira de Pesquisa sobre Formação Docente, v.2, n.3, p.11-49, ago./dez. 2010. Disponível em: https://revformacaodocente.com.br/index.php/rbpfp/article/view/17/15. Acesso em: 1 mai. 2020.

HUBERMAN, M. O ciclo de vida profissional dos professores. In: NÓVOA, A. (org.). Vidas de professores. 2. ed. Porto: Porto, 2000. p.31-61.

NÓVOA, A. Entrevista concedida à Lucíola Licínio Santos. Educação em Perspectiva, Viçosa, v.4, n.1, p.224-237, jan./jun. 2013. Disponível em:

https://periodicos.ufv.br/educacaoemperspectiva/article/view/6637/2742. Acesso em: 13 fev. 2021.

NÓVOA, A. Firmar a posição como professor, afirmar a profissão docente. Caderno de Pesquisa v.47, n.166, p.1106-1133, out./dez.2017. Disponível em: https://www.scielo.br/j/cp/a/WYkPDBFzMzrvnbsbYjmvCbd/?lang=pt\&format=pdf. Acesso em: 14 set. 2021. 
PASSOS, L. F.; ANDRADE, M. F. R.; APARICIO, A. S. M.; COSTA, E. C. S. Comunidades de aprendizagem e práticas colaborativas nos processos de inserção profissional. Revista Eletrônica de Educação, v.14, p.1-18, e4261115, jan./dez. 2020. Disponível em: http://www.reveduc.ufscar.br/index.php/reveduc/article/view/4261/1083. Acesso em: 14 set. 2021.

PRÍNCIPE, L.; ANDRÉ, M. Condições de trabalho na fase de indução profissional dos professores. Currículo sem fronteiras, v.19, n.1, p. 60-80, jan/abr.2019. Disponível em:

https://www.curriculosemfronteiras.org/vol19iss1articles/princepe-andre.pdf. Acesso em: 14 set. 2021.

ROMANOWSKI, J. P.; MARTINS, P. L. O. Desafios da formação de professores iniciantes. Pág. Educ., Montevideo, v.6, n.1, p.83-96, jun.2013. Disponível em:

http://www.scielo.edu.uy/scielo.php?script=sci_arttext\&pid=S1688-74682013000100005. Acesso em: 11 mar. 2020.

SHULMAN, L. S. Conhecimento e ensino: fundamentos para a nova reforma. Cadernos Cenpec; Pesquisa e Ação Educacional, v.4, n.2, p.196-229, dez. 2014. Disponível em:

http://cadernos.cenpec.org.br/cadernos/index.php/cadernos/article/view/293. Acesso em: 11 mar. 2020.

WONG, H. K. Induction programs that keep new teaching and improving. NASSP Bulletin, v.88, n.638, p.41-58, mar. 2004.

Recebido em março 2021.

Aprovado em setembro 2021. 